\title{
Geographic Information System for Selection of Freshwater Fish Cultivation Land Using Logic Scoring of Preference (LSP) Method
}

\author{
Dovel Pirmanto \\ Master of Information System \\ Diponegoro University \\ Semarang, Indonesia
}

\author{
Jatmiko Endro Suseno \\ Department of Physics \\ Diponegoro University \\ Semarang, Indonesia
}

\author{
Kusworo Adi \\ Department of Physics \\ Diponegoro University \\ Semarang, Indonesia
}

\begin{abstract}
Determining the right land for fish farming is very influential in achieving optimal land productivity to reduce the impact of time and financial losses. This thesis study aims to develop a Geographic Information System for the Selection of Freshwater Fish Farming Land Using the Logic Scoring of Preference (LSP) Method. Analysis of land suitability data using the LSP method, the results as a material for decision making in land selection. LSP method has a consistency with properties that can be observed from consideration of human evaluation. The results of this study are in the form of a system that can be used for the selection of fish cultivation land based on the LSP method and visualized in the Geographic Information System (GIS). The results of the calculation of land suitability of thirty-six alternative land in the case study in Kerinci Regency, then obtained alternative land that has a high level of suitability Pendung Mudik the suitability value of 0.96 is the best alternative based on LSP calculation results. Validation of LSP calculation and expert assessment is $80,55 \%$.
\end{abstract}

\section{General Terms}

Decision Support System, Geographic Information System.

\section{Keywords}

Logic Scoring of Preference (LSP), Fish Cultivation, Geographic Information System.

\section{INTRODUCTION}

Food security is a challenge for every country, this is due to increasing food needs for every human being. Aquaculture is one of the agribusiness that has a rapid development, and will be the main supplier of future animal protein needs.

Previous research has developed a Multicriteria Evaluation (MCE) to evaluate land suitability with the Logic Scoring of Preference (LSP) and GIS methods for evaluating the suitability of urban land use. Application of the LSP method to evaluate the suitability of urban land using a large number of evaluation criteria and human reasoning. The LSP method has a consistent, observable nature of human judgment considerations, the ability of the LSP method to enter a large number of inputs while maintaining the importance of each input during multicriteria evaluation [1].

At present the determination of land is still traditionally carried out or just looking at past criteria of experience is not based on criteria set by competent agencies or agencies. This can be a mistake in determining the selected land which results in losses, both in terms of time and financially. Optimal land productivity is very influential in determining the right land to ensure sustainable land growth, so that effective decision making requires information [2]. The factor that greatly influences the success and sustainability of aquaculture is site selection. AHP method is used to identify factors that influence shrimp farming, among others: water quality, soil characteristics and infrastructure facilities. Integration of Multicriteria Evaluation (MCE) and Geographic Information System (GIS) can assist in decision making processes [3].

Multicriteria Evaluation (MCE) was developed with the Ordered Weighted Averaging (OWA) and GIS methods. This study was conducted to evaluate the location of the risk level of low or high risk geothermal prospects by determining the OR value, decision makers can control the level of risk and produce a map of low or high risk geothermal prospects and develop geothermal prospects ranging from pessimistic to optimistic strategies. These results in a more accurate geothermal perspectivity map [4].

The use of the AHP and OWA methods in previous research cannot capture a large number of environmental criteria needed to adequately evaluate complex problems [1]. Therefore, the study was conducted to expand the GIS-based MCE method by using the Logic Scoring of Preference (LSP) method to incorporate a large number of criteria into a flexible and adaptive structure by adding field criteria and accessibility to evaluate land suitability for semah fish farming. Another difference is that the determination of aggregators in this study was carried out by the Fisheries Service to calculate the value of the suitability of each alternative.

\section{REALATED WORK}

The application of the Logic Scoring of Preference (LSP) and GIS methods can be used to assess water resistance to nitrates from agricultural land. The use of evaluation models using GIS-based Logic Scoring of Preference (LSP) methods can identify areas with five categories of vulnerability, taking into account the hydrogeological and environmental characteristics of the region as a whole and identifying areas with varying levels of risk of nitrate pollution. So that it can provide guidance on the risk of nitrate pollution and pay attention to areas that require specific research and nitrogen reduction [5].

Dragicevic's research on the implementation of the Multicriteria evaluation (MCE) method was used for urban geo simulation decision making. Multicriteria evaluation (MCE) was developed with the Logic Scoring of Preference (LSP) and GIS models to model various aggregators to adapt various evaluation objectives that are close to human reasoning. The LSP method can collect an unlimited number of inputs without losing significance. The LSP method can capture the decision-making reasoning of different agents that are closer to human logic which has produced modeling results of urban housing use to fit the long-term city plan [6]. 
Montgomery's research on the application of Logic Scoring of Preferences (LSP) and GIS to evaluate the suitability of urban land use. Application of Logic Scoring of Preference (LSP) to evaluate the suitability of urban land by using a large number of evaluation criteria and human reasoning. Research shows that soft computing methods and especially LSP do the best among GIS-based MCE methods for urban land use applications [1].

\section{TRESEARCH METHODOLOGY}

\subsection{Geographic Information System}

Geographic information system (GIS) is a tool that can be used to manage (enter, process and output.) spatial data or data that refers to geographical and spatial conditions. Spatial data is data that refers to locations on the surface of the earth, for example data on the distribution of sampling locations, road network data of a city, population density data of an area and so on. Large amounts of geospatial data are collected and stored using a combination of database management. The layer or map layer serves to describe the relationship between geospatial data in two and three dimensions in the form of maps, and to determine the relationship between entities of each data used in geographic information systems [7].

Geographical information system is the process of collecting, storing, processing and analyzing and presenting data or information from an object, an event that has a connection with the location and existence of an object on the surface of the earth using computer-based technology or a system. Data input, data processing or analysis, release and analysis results, and data management are part of a geographic information system sub-system that is interrelated [8].

\subsection{Logic Scoring of Preference}

The Logic Scoring of Preference (LSP) method is the MCE method that was introduced in the early 1970s. The mathematical foundation of the LSP method is based on concepts of soft conjunction/disjunction computing. The use of the LSP method for calculating conformity in conformity maps was first proposed in [9].

The LSP method was developed as an approach to combining criteria with the aim of maintaining the logic of human decision making. Human decision making is represented by simultaneous scale inclusion of continuity and the ability to replace used when combining criteria, features that are not available in other general-based MCE GIS. The application of GIS-based MCE methods in land suitability evaluations can rarely include a large number of diverse criteria (more than 10 criteria) and discuss a wider range of logics of human decision making [10].

The Logic Scoring of Preference (LSP) method was developed to provide a better component for overcoming shortcomings in the previous MCE method. LSP uses soft computational logic operations of partial connection / strong and weak partial disjunction and conjunctive and disjunctive partial absorption, human reasoning is more represented [9]. The LSP method has three main steps: (1) developing attribute trees (2) defining basic attribute criteria, and (3) developing logic aggregation structures.

\section{Tree of Attribute LSP}

The LSP attribute tree manages decision problems and contains all relevant attributes and parameters. All input criteria are needed in determining the order in which the input will be combined together, to the point where all input criteria have been combined together. Figure 2.2 shows an example of a simple attribute tree with four sample inputs, the input criteria are grouped into a category A or category B. A sum is that inputs $\mathrm{A} 1$ and $\mathrm{A} 2$ are more similar to each other than inputs B1 or B2, and vice versa. Node A represents the combination of inputs $\mathrm{A} 1$ and $\mathrm{A} 2$ Node B represents a combination of inputs $\mathrm{B} 1$ and $\mathrm{B} 2$, while a node $\mathrm{AB}$ represents a combination of all four inputs. The LSP aggregation structure obtained from each node (A, B and $\mathrm{AB}$ ) has an LSP aggregator [6]. Each mandatory input is combined with other mandatory inputs, resulting in a representation node of the two mandatory inputs, then combining mandatory inputs with optional inputs.

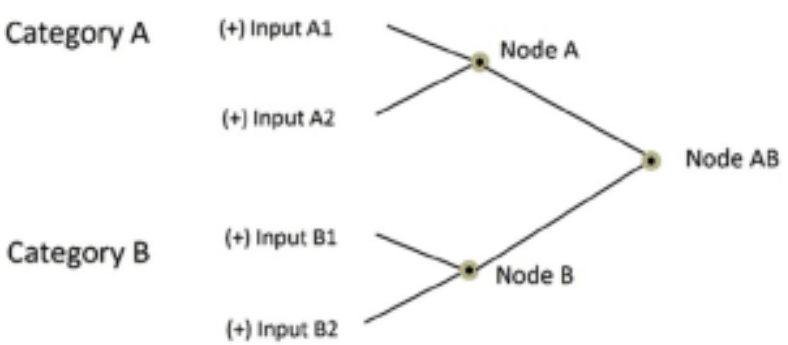

Fig 1: Example attribute tree

\section{Defining basic attribute criteria}

The input attributes are separately evaluated using basic attribute criteria. The basic attribute criteria represent stakeholder requirements that must be met by input attributes [1]. Case examples of water brightness (the first attribute in the chemical parameter group) to describe the definition of basic attribute criteria, that in the fish cultivation process the level of satisfaction will be achieved when meeting the standard values based on SNI 8228.4 is brightness $\geq 38 \mathrm{~cm}$ with a maximum weight value of 1 . As a result, if brightness $<38 \mathrm{~cm}$, the level of satisfaction with water brightness is less than the maximum value of 1 .

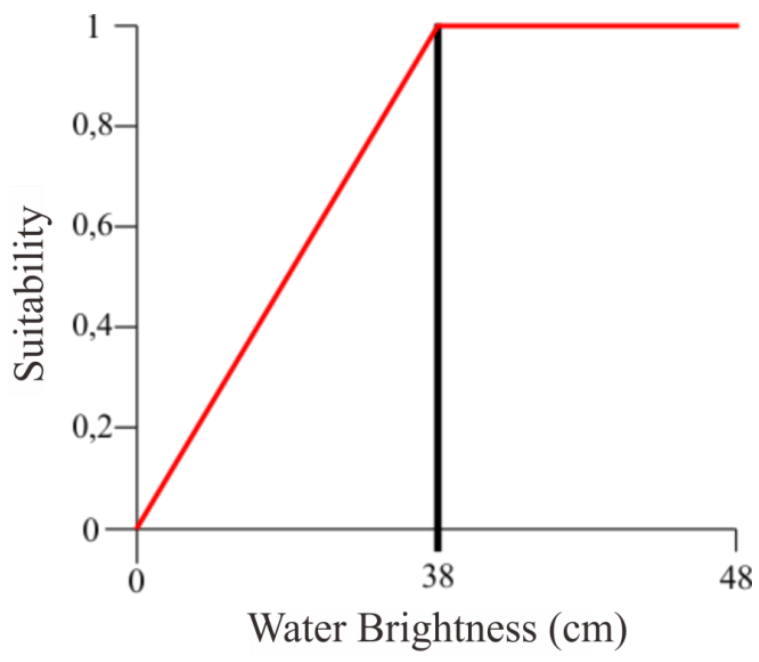

Fig 2: Example function attribute criteria

The function of this criterion can be presented graphically as the graph shown in Fig.2 The value of $38 \mathrm{~cm}$ are obtained from the standard value used and is the minimum value found based on water quality. If more precise information about requirements is available, these criteria can be further refined.

\section{Aggregation structures}

Aggregator is a combination of input attributes by using the exponent value of the aggregator shown in Fig 3, after applying the basic criteria for $\mathrm{n}$ input attributes produces a level of conformity of attributes (interpreted as degrees of 
truth or membership). The next step is to combine the level of suitability of these attributes to produce an overall level of conformity that reflects the quality of the entire object being evaluated. The next step of the LSP method is to develop an aggregation structure that combines the level of suitability of attributes, taking into account the objectives and requirements of certain stakeholders. These requirements affect the selection of logical aggregation operators and the relative importance of each attribute and group [10].

\begin{tabular}{|c|c|c|c|}
\hline & Aggregator & Exponent $r$ & \multirow{9}{*}{ Partial disjunction } \\
\hline \multirow{8}{*}{ Replaceability } & D & $+\infty$ & \\
\hline & D++ & 20.63 & \\
\hline & D+ & 9.521 & \\
\hline & D+- & 5.802 & \\
\hline & DA & 3.929 & \\
\hline & D-+ & 2.792 & \\
\hline & D- & 2.018 & \\
\hline & D- - & 1.449 & \\
\hline \multirow[t]{4}{*}{ Neutrality } & $\mathbf{A}$ & 1 & \multirow{4}{*}{$\begin{array}{l}\text { Nonmandatory } \\
\text { requirements (soft } \\
\text { partial conjunction) }\end{array}$} \\
\hline & C- - & 0.619 & \\
\hline & C- & 0.261 & \\
\hline & C-+ & -0.148 & \\
\hline \multirow[t]{5}{*}{ Simultaneity } & CA & -0.72 & \multirow{5}{*}{$\begin{array}{l}\text { Mandatory } \\
\text { requirements (hard } \\
\text { partial conjunction) }\end{array}$} \\
\hline & $\mathrm{C}+-$ & -1.655 & \\
\hline & C+ & -3.51 & \\
\hline & $\mathrm{C}++$ & -9.06 & \\
\hline & c & $-\infty$ & \\
\hline
\end{tabular}

Fig 3: Agregator

Determination of a aggregator is the basis for determining the rank or exponent value for input attributes then it will be combined together with the generalized conjunction disjunction (GCD) equation:

$\operatorname{GCD}\left(\mathrm{X}_{1}, \ldots \ldots \mathrm{X}_{\mathrm{n}}\right)=\left(\mathrm{W}_{1} \mathrm{X}_{1}{ }^{\mathrm{r}}+\ldots+\mathrm{W}_{\mathrm{n}} \mathrm{X}_{\mathrm{n}}{ }^{\mathrm{r}}\right)^{1 / \mathrm{r}}$

All inputs are collected in the same way throughout the aggregation structure until one output value is determined. When combining mandatory and optional inputs, and using Conjunctive Partial Absorption (CPA). The CPA function was introduced by Dujmovic' (1979). Suitability of S output is calculated by combining mandatory $\mathrm{X}$ input and optional $\mathrm{Y}$ input as follows:

$\mathrm{S}(\mathrm{X}, \mathrm{Y})=\left\{\left(1-\mathrm{W}_{2}\right)\left[\mathrm{W}_{1} \mathrm{X}^{\mathrm{r} 1}+\left(1-\mathrm{W}_{1}\right) \mathrm{Y}^{\mathrm{r} 1}\right]^{\mathrm{r} 1 / \mathrm{r} 2}+\mathrm{W}_{2} \mathrm{X}^{\mathrm{r} 2}\right\}^{1 / \mathrm{r} 2}$

Weights $\mathrm{W} 1$ and $\mathrm{W} 2$ were obtained from the calculation of the function of the attribute criteria and exponents of r1 and r2 obtained from the aggregator determination. To illustrate the use of CPA, consider examples of terrain evaluation in the context of evaluating land capabilities with different weights.

Overall, each LSP structure in the study applies a combination of GCD and CPA functions to mathematically represent simultaneity, ability to replace and aggregate from mandatory and optional inputs. These functions are used mainly due to the fact that this research requires mandatory and optional criteria and does not have sufficient input that will require disjunctive functions. The importance of each attribute criterion in the LSP structure is represented by the given weight applied during aggregation, the higher level of influence corresponding to the higher weight value. Values for weights come from previous land feasibility studies and expert knowledge obtained from soil scientists [1].

\subsection{Tstandards for Determining Land for Freshwater Fish Cultivation}

The appropriate standards for selecting freshwater fish farms are as follows:

Table 1. Standards for Determining Land for Freshwater Fish Cultivation

\begin{tabular}{|c|c|c|}
\hline Category & Criteria & $\begin{array}{c}\text { Standard } \\
\text { Value }\end{array}$ \\
\hline \multirow{2}{*}{ Field } & Slope & $8 \%$ \\
\cline { 2 - 3 } & Height & $500 \mathrm{mdpl}$ \\
\hline \multirow{4}{*}{$\begin{array}{c}\text { Chemical } \\
\text { Parameters }\end{array}$} & Water Brightness & $38 \mathrm{~cm}$ \\
\cline { 2 - 3 } & $\mathrm{pH}$ & $6-8$ \\
\cline { 2 - 3 } & Ammonia & Max 1 \\
\cline { 2 - 3 } & Nissolved oxygen & Min 4 \\
\hline \multirow{4}{*}{ Climate } & Temperature & $25-30^{\circ} \mathrm{C}$ \\
\cline { 2 - 3 } & Flood & Not flooded \\
\hline \multirow{3}{*}{ Accessibility } & $\begin{array}{c}\text { Distance to } \\
\text { Irrigation }\end{array}$ & $500 \mathrm{~m}$ \\
\cline { 2 - 3 } & Distance to Road & $500 \mathrm{~m}$ \\
\hline \multirow{2}{*}{ Land capability } & Drainage & $>141 / \mathrm{sec}$ \\
\cline { 2 - 3 } & Water availability & Irrigation \\
\hline
\end{tabular}

\section{RESULTS AND DISCUSSION}

This research data uses secondary data in the form of parameter measurement data and alternative variables for fish farming. Spatial data (regional boundary maps, land coordinates, topographic maps, slope data, altitude, distance to irrigation, distance to main roads, drainage), non-spatial data (parameters of fish farming land).

The initial stage in processing data is by digitizing all data so as to produce digital maps using the Quantum GIS 2.18 devices so that the digital maps used have coordinates according to the actual conditions and generate shape file data format (shp). Spatial data that has been digitalized to produce vector-based spatial data is used to display information about fish cultivation in line and village boundary polygons that appear on the map. The process of data manipulation with the logic scoring of preference method will be converted to data databases, to provide easy manipulation of the data. The next stage translates each function into the logic scoring of preference method into the PHP programming language with the following steps:

\section{Determination of Attribute Trees}

The attribute tree is used to determine the decomposition structure that produces all the attributes that characterize the evaluated object. The parameters for selecting fish farms will be categorized and then decomposed into criteria for determining fish farming land. The criteria for determining land are categorized as terrain, chemical parameters, climate, accessibility and land capability. In the field categories decomposes into, slope and altitude. The categories of chemical parameters are decomposed into; water brightness, $\mathrm{pH}$, ammonia, dissolved oxygen and nitrate. The climate 
category decomposes into, temperature and water. The accessibility category decomposes into, the distance to irrigation and the distance to the main road. The ability category decomposes into drainage and water availability. The next stage is to determine each criterion that has been determined to be a mandatory and optional criterion.

LSP attribute tree is a decomposition structure that produces all attributes that characterize the evaluated object. At each level the decomposition process consists of defining the categories of compound items analyzed. For example, suitability for fish cultivation is decomposed into terrain, chemical parameters, climate, accessibility and land capability. From the decomposition, will be decomposition carried out again to produce a number of criteria. From the field category decomposed into the slope and altitude, from the two criteria resulting from field category decomposition, there is one mandatory input (+), namely slope (K1) and there is one optional input (-) namely altitude (K2).

In the category of chemical parameters decomposed into water brightness (K3), $\mathrm{pH}(\mathrm{K} 4)$, ammonia (K5), dissolved oxygen (K6) and nitrate (K7). From the results of the decomposition of the chemical parameter categories, all of these criteria are mandatory $(+)$ criteria. The climate category is decomposed into temperature (K8) and flood (K9), both of these criteria are mandatory $(+)$ criteria. The accessibility category is decomposed into the distance of land to irrigation (K10) and the distance of land to the main road (K11), both of these criteria are mandatory (+) criteria. The ability category of land is decomposed into drainage (discharge) (K12) and water availability (K13), both of these criteria are mandatory criteria $(+)$.

\section{Kriteria atribut}

The attribute criteria represent the requirements of the Fisheries Service that must be fulfilled by each land. The attribute criterion is used to determine the weight value of each criterion using a predetermined range value and refers to the standard value.

\section{Agregator}

The aggregator will be determined by stakeholders, namely the Fisheries Service Office of Kerinci Regency, in this study the aggregators used are $\mathrm{C}-+, \mathrm{C}--, \mathrm{CA}, \mathrm{C}+-$, and $\mathrm{C}+$. Determination of aggregators based on the level of importance and influence of criteria on the suitability of freshwater fish farming land. Based on the 13 established criteria, there are 12 compulsory criteria that use $\mathrm{C}-+, \mathrm{CA}, \mathrm{C}+-$ and $\mathrm{C}+$ aggregators while in this study there are 1 optional criterion that uses the C-- aggregator. The use of aggregators on each criterion to combine the two criteria so that it has a representation value or a combined value of these inputs.

In this study using CA aggregators for the category of land chemical parameters because the land chemical parameters have a higher importance than other categories, so using aggregators that are stronger than $\mathrm{C}-+$. Use of $\mathrm{C}+$ aggregators - to combine multiple categories so that aggregator values are stronger than aggregators when combining one category. The
$\mathrm{C}+$ aggregator is used to combine all the criteria from each category, so that the use of $\mathrm{C}+$ aggregators becomes the representation value of all criteria for land selection.

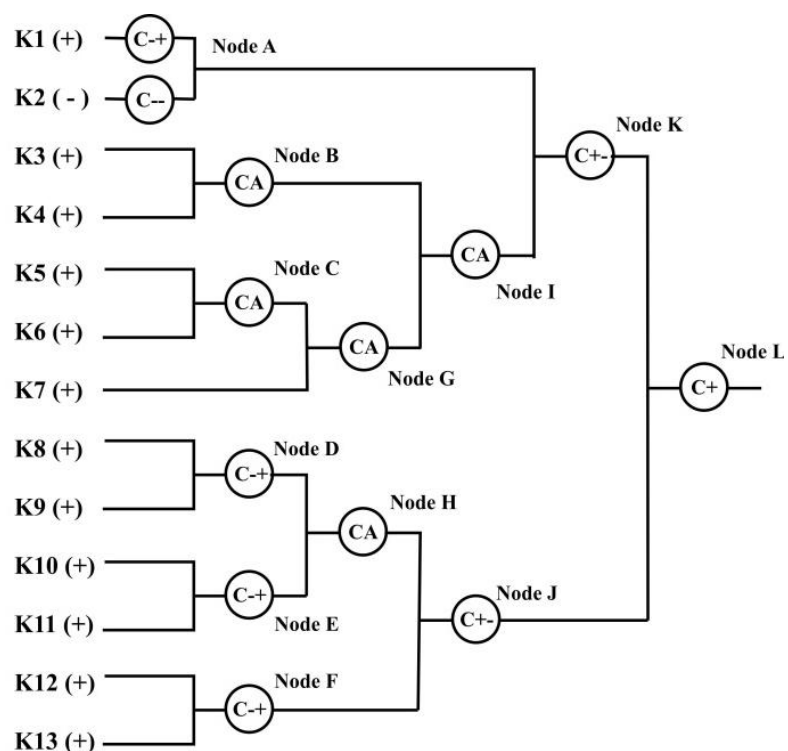

Fig 4: Aggregation structure or aggregator

In one alternative land 1 which has a water brightness (K3) of $29 \mathrm{~cm}$, the value of the attribute criteria or weight is 0.76 . Land 1 has a $\mathrm{pH}(\mathrm{K} 4) 7$, then the attribute criterion value or weight is 1 . Both of these criteria are mandatory criteria with $\mathrm{CA}$ aggregators and $\mathrm{r}$ values of -0.72 . Criteria $\mathrm{K} 3$ and $\mathrm{K} 4$ are combined to get the value of representation of the two criteria.

$\mathrm{B}(\mathrm{K} 3, \mathrm{~K} 4) \quad=\left(0,76^{-0,72}+1^{-0,72}\right)^{1 /-0,72}=0,331$

The result of the calculation is a value that represents the criteria of $\mathrm{K} 3$ and $\mathrm{K} 4$ which are the criteria for chemical parameters in alternative land 1 , the value will be combined with all values of each chemical parameter. Criteria K5 and K6 are combined to obtain the value of representation.

$\mathrm{C}(\mathrm{K} 5, \mathrm{~K} 6)$

$$
=\left(1^{-0,72}+0,5^{-0,72}\right)^{1 /-0,72}=0,259
$$

Criteria $\mathrm{K} 8$ and $\mathrm{K} 9$ are combined to obtain the representation value of criteria in the climate category for land 1 . So that the combined values of $\mathrm{K} 8$ and $\mathrm{K} 9$ produce values from a node $\mathrm{D}$.

$\mathrm{D}(\mathrm{K} 8, \mathrm{~K} 9) \quad=\left(0,84^{-0,148}+1^{-0,148}\right)^{1 /-0,148}=0,008$

Node $\mathrm{L}$ is a suitability value for each land alternative from the LSP calculation by combining 11 nodes based on predefined attribute and aggregator trees from 13 land criteria for each alternative. The combined value of all criteria from each node results in land suitability values for fish farming.

So that node $\mathrm{L}$ becomes the final value of land suitability for freshwater fish cultivation. The scale of the land suitability level is Very Good (1 - 0.86), Good (0.85 - 0.71), Enough (0.70 - 0.57), Bad (0.56 - 0.43), and Very Bad (0.1 - 0.43) [1]. 
Table 2. The results of the calculation of land suitability with the LSP method

\begin{tabular}{|c|c|c|c|c|c|}
\hline Id Land & Value & Suitability & Id Land & Value & Suitability \\
\hline 1 & 0,84 & Good & 121 & 0,82 & Good \\
\hline 6 & 0,58 & Enough & 122 & 0,66 & Enough \\
\hline 7 & 0,77 & Good & 125 & 0,82 & Good \\
\hline 11 & 0,68 & Enough & 127 & 0,84 & Good \\
\hline 17 & 0,52 & Bad & 130 & 0,76 & Good \\
\hline 18 & 0,83 & Good & 133 & 0,94 & Very Good \\
\hline 20 & 0,77 & Good & 134 & 0,67 & Enough \\
\hline 23 & 0,70 & Enough & 136 & 0,83 & Good \\
\hline 40 & 0,69 & Enough & 139 & 0,69 & Enough \\
\hline 49 & 0,81 & Good & 143 & 0,84 & Good \\
\hline 56 & 0,93 & Very Good & 163 & 0,64 & Enough \\
\hline 61 & 0,82 & Good & 183 & 0,62 & Enough \\
\hline 72 & 0,79 & Good & 185 & 0,68 & Enough \\
\hline 76 & 0,51 & $\mathrm{Bad}$ & 198 & 0,77 & Good \\
\hline 89 & 0,96 & Very Good & 199 & 0,82 & Good \\
\hline 93 & 0,54 & Bad & 201 & 0,74 & Good \\
\hline 101 & 0,69 & Enough & 202 & 0,68 & Enough \\
\hline 103 & 0,76 & Good & 210 & 0,83 & Good \\
\hline
\end{tabular}

d] Pemilihan Lahan

\section{G GEOGRAPHIC INFORMATION SYSTEM SELECTION OF FRESH WATER FISH CULTIVATION}

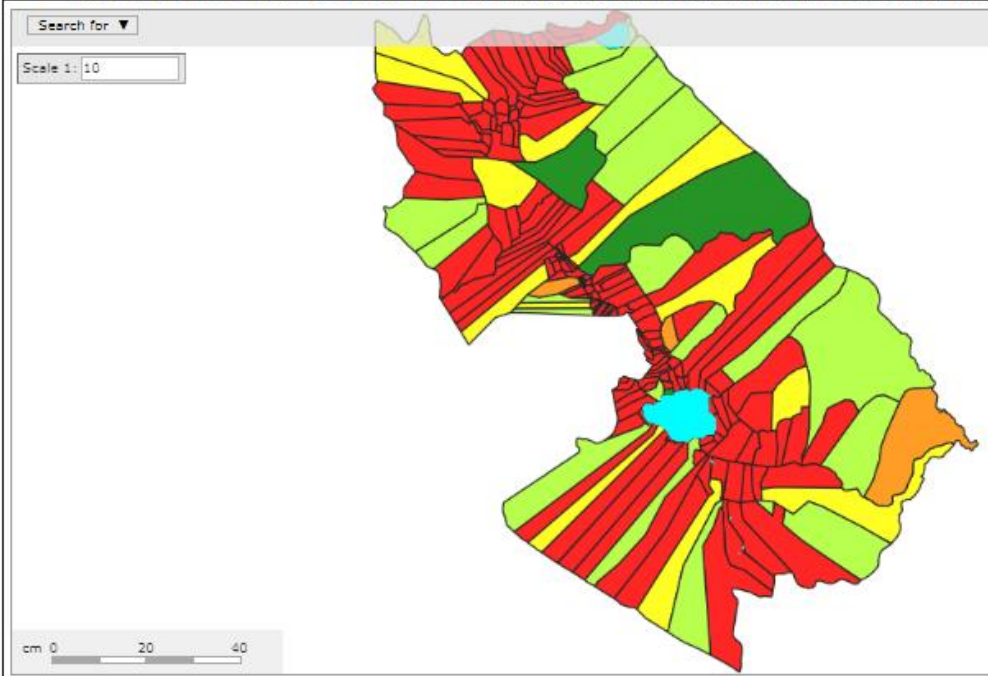

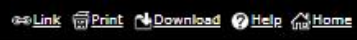

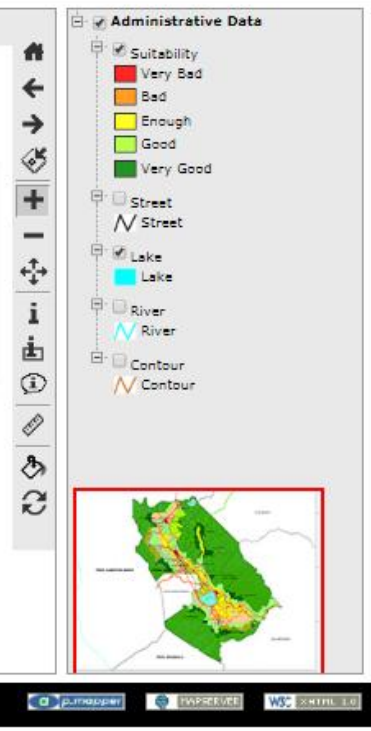

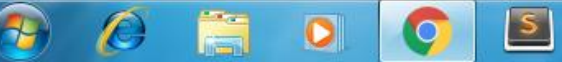

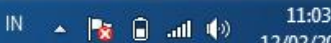

Fig 5: The results of the calculation of the suitability value of thirty-six alternative land areas are visualized into GIS 


\section{CONCLUCION}

Based on the results of research and discussion that the geographic information system selection of freshwater fish farming land with the logic scoring of preference method can determine the level of suitability of land for freshwater fish cultivation. The calculation results of the land suitability of the thirty-six alternative land available as the research sample, there are 3 fields that have a high level of suitability or are very good to be used as land for aquaculture, 18 fields in a good scale, 12 fields in enough scale and 3 fields in an bad scale, an alternative land that has a high level of suitability is found Pendung Mudik, the conformity value 0.96 as the best alternative. Land suitability validation with LSP calculation and expert assessment, there are 29 valid or appropriate fields of LSP calculation results and expert assessment results. There are 6 fields that are invalid or incompatible between LSP calculation results and expert assessment results, thus from 36 fields that become alternatives there are 29 valid fields or according to expert judgment so that the validation of LSP calculation and expert assessment is $80,55 \%$. The visualization process of geoprocessing data in Kerinci Regency map can represent the results of calculation of the level of land suitability in each alternative into geographic information systems with data in the form of vectors and layers.

\section{ACKNOWLEDGMENTS}

The author would lika to thank all those who helped in this research. Especially the Fisheries Service Office of Kerinci Regency, Jambi Province, Indonesia, because it was willing to be the data source for this research.

\section{REFERENCES}

[1] Montgomery, B., Suzana D. 2016. Comparison of GISBased Logic Scoring of Preference and Multicriteria Evaluation Methods: Urban Land Use Suitability. Geographical analysis. 48(4), 427-447.

[2] Li, H., Aide T. M., Ma, Y., Liu W., dan Cao, M. 2016. Demand for rubber is causing the loss of high diversity rain forest in SW China, Biodiversity and Conservation, 16(6), 1731-1745.

[3] Hossain, M.S., Das, N.G. 2010. GIS-based multi-criteria evaluation to land suitability modelling for giant prawn (Macrobrachium rosenbergii) farming in Companigonj Upazila of Noakhali, Bangladesh. Comput. Electron. Agric. 70 (1), 172-186.

[4] Kiavarz, Majid., Mohammadreza J. N., 2017, Geothermal prospectivity mapping using GIS-based Ordered Weighted Averaging approach: A case study in Japan's Akita and Iwate provinces. Geothermics. 70, 295-304.

[5] Rebolledo, B., Antonia G, Xavier F, Jos E. 2016. Assessment of groundwater vulnerability to nitrates from agricultural sources using a GIS-compatible logic multicriteria model. Journal of Environmental management. 172, 70-80.

[6] Dragicevi , S., Hatch, H. 2018. Urban Geosimulations with the Logic Scoring of Preference method for agentbased decision-making. Habitat International, 72, 3-17.

[7] Vatsavai, R., S. Shekhar, T. E. Burk, Lime, S. 2014. Mapserver : A high performance, interoperable, and open source web mapping and geo-spatial analysis system, Geographic Information Science. 400-4017.

[8] Sample, J. E., Baber, I., Badger, R. 2016. A spatially distributed risk screening tool to assess climate and land use change impacts on water-related ecosystem services, Enviromental Modelling \& Software. 83, 12-26.

[9] Dujmovic' , J.J., Tré, G.De., Van de Weghe, N. 2008. Suitability maps based on the LSP method. Model. Decis. Artif. Intell. 15-25.

[10] Dujmovic' , J., De Tré, G., Dragic'evic' , S. 2009. Comparison of multicriteria methods for land-use suitability assessment. In: 2009 IFSA World Congress/EUSFLAT Conference. 1404-1409. 